\author{
BARANETSKIJ YA.O. ${ }^{1}$, IVASIUK I.YA. ${ }^{2}$, KALENYUK P.I. $^{1}$, SOLOMKO A.V. ${ }^{2}$
}

\title{
THE NONLOCAL BOUNDARY PROBLEM WITH PERTURBATIONS OF ANTIPERIODICITY CONDITIONS FOR THE ELLIPTIC EQUATION WITH CONSTANT COEFFICIENTS
}

\begin{abstract}
In this article, we investigate a problem with nonlocal boundary conditions which are perturbations of antiperiodical conditions in bounded $m$-dimensional parallelepiped using Fourier method. We describe properties of a transformation operator $R: L_{2}(G) \rightarrow L_{2}(G)$, which gives us a connection between selfadjoint operator $L_{0}$ of the problem with antiperiodical conditions and operator $L$ of perturbation of the nonlocal problem $R L_{0}=L R$.

Also we construct a commutative group of transformation operators $\Gamma\left(L_{0}\right)$. We show that some abstract nonlocal problem corresponds to any transformation operator $R \in \Gamma\left(L_{0}\right): L_{2}(G) \rightarrow L_{2}(G)$ and vice versa. We construct a system $V(L)$ of root functions of operator $L$, which consists of infinite number of adjoint functions. Also we define conditions under which the system $V(L)$ is total and minimal in the space $L_{2}(G)$, and conditions under which it is a Riesz basis in the space $L_{2}(G)$.

In case if $V(L)$ is a Riesz basis in the space $L_{2}(G)$, we obtain sufficient conditions under which the nonlocal problem has a unique solution in the form of Fourier series by system $V(L)$.

Key words and phrases: differential-operator equation, eigenfunctions, Riesz basis.
\end{abstract}

\footnotetext{
${ }^{1}$ Lviv Polytechnic National University, 12 Bandera str., 79013, Lviv, Ukraine

${ }^{2}$ Vasyl Stefanyk Precarpathian National University, 57 Shevchenka str., 76018, Ivano-Frankivsk, Ukraine

E-mail: baryaromeukr.net (Baranetskij Ya.O.), vanobsb@gmail .com (Ivasiuk I.Ya.), kalenyuk@lp.edu.ua (Kalenyuk P.I.), ansolvas@gmail.com (Solomko A.V.)
}

\section{INTRODUCTION}

Investigation of ordinary differential equations with nonlocal integral conditions begins in works of H. Birkoff, A. Zommerfeld, J. Stone, Ya.D. Tamarkin, W. Feller. Fundamental role in development of nonlocal problems and shift operator theory play works of T. Carleman. The general theory of elliptic boundary problems was formed due to investigations of Y.G. Beid and R.S. Friman, R. Bills, F. Brauder, L. Ehrenpreis, L. Hermander, G. Grub, J.W. Kalkin, Ya.B. Lopatynskiy, M. Malgrange, I.V. Skrypnyk, M. Shekhter, M.I. Vishyk. Nonlocal boundary problems for linear differential equations with partial derivatives in different aspects were investigated by Yu.M. Berezanskiy, A.V. Bitsadze, V.M. Borok, M.L. Gorbachuk, O.O. Dezin, Yu.M. Dybinskiy, M.I. Ionkin, V.S. Ilkiv, P.I. Kalenuyk, A.H. Mamyan, V.A. Mykhailets, B.Yo. Ptashnyk, V.K. Romanko, O.A. Samarskiy, O.L. Skubatchevkiy, S.Ya. Yakubov. Nonlocal elliptic problems were studied in works of A.V. Bitsadze, O.O. Dezin, A.I. Kamynin, S.A. Paneyakha, Ya.A. Roytberg and Z.G. Sheftel, A.A. Samarskiy, L.A. Skybatchevkiy and their followers. 
This paper is denoted to research of nonlocal problems for equations with constant coefficients. The classes of uniqueness and existence of the solution of boundary value problems in unbounded domains (half-space, unbounded strip) for equations with constant coefficients were studied in $[7,8,11,12,17,22-26]$.

Boundary value problems in bounded domains for certain classes of differential equations with constant coefficients have been studied in $[1,9,10,13-16,18,20,21,27,28]$. The work is a continuation of the studies begun in [2-6].

Let us denote $\mathbb{Z}_{0}:=\{k: k \geq 0, k \in \mathbb{Z}\}, \beta=\left(\beta_{1}, \beta_{2}, \ldots, \beta_{m}\right) \in \mathbb{Z}_{0}^{m},|\beta|=\beta_{1}+\ldots+\beta_{m}$,

$$
\begin{aligned}
& G:=\left\{x=\left(x_{1}, x_{2}, \ldots, x_{m}\right) \in \mathbb{R}^{m}: 0<x_{j}<X_{j}<\infty, j=1,2, \ldots, m\right\}, \\
& G_{r}:=\left\{x^{r}=\left(x_{1}, \ldots, x_{r-1}, x_{r+1}, \ldots, x_{m}\right) \in \mathbb{R}^{m-1}: 0<x_{j}<X_{j}<\infty, j \neq r, j=1,2, \ldots, m\right\} .
\end{aligned}
$$

Let $D_{j}$ be the operator of differentiation by variable $x_{j}$. Denote $D^{2 \beta}:=D_{1}^{2 \beta_{1}} D_{2}^{2 \beta_{2}} \cdot \ldots \cdot D_{m}^{2 \beta_{m}}$, $W_{2}^{2 n}(G):=\left\{y \in L_{2}(G): D^{2 \beta} y \in L_{2}(G),|\beta|=n\right\}$,

$$
\left(y, z ; W_{2}^{2 n}(G)\right):=\sum_{j=1}^{m}\left(D_{j}^{2 n} y, D_{j}^{2 n} z ; L_{2}(G)\right), \quad\left|y ; W_{2}^{2 n}(G)\right|^{2}:=\sum_{j=1}^{m}\left(D_{j}^{2 n} y, D_{j}^{2 n} y ; L_{2}(G)\right) .
$$

Also we will use the following notations. Let $E_{j}$ be the identical transformation in the space $L_{2}\left(0, X_{j}\right) ; E$ be the identical transformation in the space $L_{2}(G) ; I_{j}$ be an operator of involution in the space $L_{2}\left(0, X_{j}\right), I_{j} z(x):=z\left(X_{j}-x\right), z(x) \in L_{2}\left(0, X_{j}\right) ; p_{j}$ be an orthoprojector in the space $L_{2}\left(0, X_{j}\right) ; p_{j} z(x):=\frac{1}{2}\left(z(x)+(-1)^{j} z\left(X_{j}-x\right)\right), z(x) \in L_{2}\left(0, X_{j}\right) ; L_{2, r}\left(0, X_{j}\right):=\left\{z\left(x_{j}\right) \in\right.$ $\left.L_{2}\left(0, X_{j}\right): z\left(x_{j}\right):=p_{r} z(x)\right\}, r=0,1 ; W_{2 n}^{*}\left(0, X_{j}\right)$ be the space of linear continuous functionals on $W_{2}^{2 n}\left(0, X_{j}\right) ; W_{2 n, s}^{*}\left(0, X_{j}\right):=\left\{l \in W_{2 n}^{*}\left(0, X_{j}\right): l\left(e^{i h x}-(-1)^{s} e^{i h\left(X_{j}-t\right)}\right)=0, h \in \mathbb{R}, x_{j} \in\right.$ $\left.\left(0, X_{j}\right)\right\}, s=0,1 ; Q_{m}:=\left\{Q:=\left(q_{1}, q_{2}, \ldots, q_{m}\right) \in \mathbb{Z}^{m}, q_{r} \in\{0,1\}, r=1,2, \ldots, m\right\} ; p_{q}:=$ $\prod_{r=1}^{m} p_{q_{r}}$ be an orthoprojector in the space $L_{2}(G) ; L_{2, Q}(G):=\left\{y \in L_{2}(G): y:=p_{Q} y\right\}$.

Let us consider boundary problem

$$
\begin{aligned}
L(D) y & :=\sum_{|\beta| \leq n}(-1)^{|\beta|} a_{\beta} D^{2 \beta} y=f, \quad x \in G, \\
\ell_{s, j} y & :=\left.D_{j}^{2 s-2} y\right|_{x_{j}=0}+\left.D_{j}^{2 s-2} y\right|_{x_{j}=X_{j}}=0, \quad j=1,2, \ldots, m, \\
\ell_{n+s, j} y & :=\left.D_{j}^{2 s-1} y\right|_{x_{j}=0}+\left.D_{j}^{2 s-1} y\right|_{x_{j}=X_{j}}+l_{s, j}^{1} y=0, \quad j=1,2, \ldots, m,
\end{aligned}
$$

where

$$
\ell_{s, j}^{1} y:=\sum_{r=0}^{1} \sum_{q=0}^{m_{s, j}} b_{q, r, s, j} D_{j}^{q} y_{x_{j}=r X_{j}},
$$

$b_{q, r, s, j} \in \mathbb{R}, q=0,1, \ldots, m_{s, j}, r=0,1, s=1,2, \ldots, n, j=1,2, \ldots, m$.

Let us denote by $L: L_{2}(G) \rightarrow L_{2}(G)$ the operator of problem (1)-(4), $L y:=L(D) y$, $y \in D(L), D(L):=\left\{y \in W_{2}^{2 n}(G): \ell_{s, j} y=0, s=1,2, \ldots, 2 n, j=1,2, \ldots, m\right\}$.

Definition 1. We will denote by function $y \in D(L)$ a solution of the problem (1)-(4) that satisfies $\left\|L y-f ; L_{2}(G)\right\|=0$. 


\section{GENERAL RESUlts}

Let us consider the following assumptions

$$
\begin{aligned}
& P_{1}: b_{q, 1, s, j}=(-1)^{q} b_{q, 0, s, j} ; \\
& P_{2}: m_{s, j} \leq 2 s-1, \quad s=1,2, \ldots, n ; \\
& P_{3}:\left|\lambda_{k}\right| \geq C_{1}|k|^{2 n}>0,0<C_{1}<\infty, k \in \mathbb{N}^{m} ; \\
& P_{4}: p_{1} X_{1}+p_{2} X_{2}+\ldots=p_{m} X_{m} \neq 0, p_{j} \in \mathbb{Z}, j=1,2, \ldots, m .
\end{aligned}
$$

Theorem 1. Let $P_{1}$ holds. Then for arbitrary numbers $a_{\beta} \in \mathbb{R},|\beta| \leq n$, the operator $L$ has eigenvalues

$$
\lambda_{k}:=\sum_{|\beta| \leq n} a_{\beta} \prod_{j=1}^{m} \rho_{k, j}^{2 \beta_{j}},
$$

$\rho_{k, j}:=\left(2 k_{j}-1\right) \pi X_{j}^{-1}, j=1,2, \ldots, m, k=\left(k_{1}, k_{2}, \ldots, k_{m}\right) \in \mathbb{N}^{m}$, and a complete and minimal system $V(L)$ of root functions exists in the space $L_{2}(G)$.

Theorem 2. Let $P_{1}-P_{2}$ hold. Then the operator $L$ has a system $V(L)$ of root functions, which is a Riesz basis for the space $L_{2}(G)$.

Theorem 3. Let the assumptions $P_{1}-P_{2}$ take place. Then for any function $f \in L_{2}(G)$ there exists a unique solution of the problem (1)-(4).

\section{SELF-ADJOINT PROBLEM FOR ORDINARY DIFFERENTIAL EQUATIONS OF EVEN ORDER}

Let us denote by $A_{0, j}$ the operator generated in $L_{2}\left(0, X_{j}\right)$ by the next boundary problem $-z^{(2)}\left(x_{j}\right)=g\left(x_{j}\right), x_{j} \in\left(0, X_{j}\right), z(0)+z\left(X_{j}\right)=0, z^{(1)}(0)+z^{(1)}\left(X_{j}\right)=0, j=1,2, \ldots, m$, $A_{0, j} y\left(x_{j}\right):=-y^{(2)}\left(x_{j}\right), y \in D\left(A_{0, j}\right)$ and $D\left(A_{0, j}\right):=\left\{y \in W_{2}^{2}\left(0, X_{j}\right): y^{(r)}(0)+y^{(r)}\left(X_{j}\right)=\right.$ $0, r=0,1\}, \tau_{1, k_{j}}\left(x_{j}\right):=\frac{2}{\sqrt{2 X_{j}}} \cos \rho_{k, j} x_{j}, k_{j}=1,2, \ldots, \tau_{0, k_{j}}\left(x_{j}\right):=\frac{2}{\sqrt{2 X_{j}}} \sin \rho_{k, j} x_{j}, k_{j}=1,2, \ldots$, $\tau_{j}:=\left\{\tau_{r, k_{j}}\left(x_{j}\right) \in L_{2}\left(0, X_{j}\right), r=0,1, k=1,2, \ldots\right\}$ is an orthonormal basis of the space $L_{2}\left(0, X_{j}\right), j=1,2, \ldots, m$.

Lemma 1. The operator $A_{0, j}$ has the point spectrum

$$
\sigma\left(A_{0, j}\right):=\left\{\mu_{k, j} \in \mathbb{R}: \mu_{k, j}=\rho_{k, j}^{2}, k=1,2, \ldots\right\}
$$

and a system of eigenfunctions $T_{j}$. Sets $L_{2, s}\left(0, X_{j}\right)$ are invariant for the operator $A_{0, j}, s=0,1$.

Proof. By substitution we obtain that $\tau_{r, k_{j}}\left(x_{j}\right) \in D\left(A_{0, j}\right)$ and $A_{0, j} \tau_{r, k_{j}}\left(x_{j}\right)=\mu_{k, j} \tau_{r, k_{j}}\left(x_{j}\right), \quad r=$ $0,1, k=1,2, \ldots$

Therefore operator $A_{0, j}$ has a system of eigenfunctions $T_{j}$, which corresponds to the set of eigenvalues $\sigma\left(A_{0, j}\right)$.

Let us notice that subset of eigenfunctions $T_{j, r}:=\left\{\tau_{r, k_{j}}\left(x_{j}\right) \in L_{2}\left(0, X_{j}\right), k=1,2, \ldots\right\}, A_{0, j}$ is an orthonormal basis in the space $L_{2, r}\left(0, X_{j}\right), r=0,1$.

Let us consider for equation (1) the following problem with boundary conditions

$$
\ell_{0, s, j} y:=\left.D_{j}^{2 s-2} y\right|_{x_{j}=0}+\left.D_{j}^{2 s-2} y\right|_{x_{j}=X_{j}}=0, s=1,2, \ldots, n, j=1,2, \ldots, m,
$$




$$
\ell_{0, n+s, j} y:=\left.D_{j}^{2 s-1} y\right|_{x_{j}=0}+\left.D_{j}^{2 s-1} y\right|_{x_{j}=X_{j}}=0, s=1,2, \ldots, n, j=1,2, . ., m .
$$

Let $L_{0}: W_{2}^{2 n}(G) \rightarrow W_{2}^{2 n}(G)$ be the operator of problem (1), (6), (7). Also we denote by $L_{0} y:=$ $L(D) y, y \in D\left(L_{0}\right) ; D\left(L_{0}\right):=\left\{y \in W_{2}^{2 n}(G): \ell_{0, s, j} y=0, s=1,2, \ldots, 2 n, j=1,2, \ldots, m\right\}$; $V\left(L_{0}\right):=\left\{v_{0, r, k}(x) \in L_{2}(G): v_{0, r, k}(x):=\prod_{j=1}^{m} \tau_{r_{j}, k_{j}}\left(x_{j}\right), r_{j} \in\{0,1\}, j=1,2, \ldots, m, k \in \mathbb{N}^{m}\right\}$

the orthonormal basis of the space $L_{2}(G) ; L_{0, Q}$ the restriction of the operator $L_{0}$ to the space $L_{2, Q}(G)$ and

$$
V_{Q}:=\left\{v_{0, q, k}(x) \in L_{2}(G): v_{0, k}(x):=\prod_{j=1}^{m} \tau_{q_{j j} j}\left(x_{j}\right), k_{j}=2 k_{j}-j_{r}, k \in \mathbb{N}^{m}\right\}, Q \in Q_{m} .
$$

Lemma 2. The operator $L_{0}$ has eigenvalues (5) and a system of eigenfunctions $V\left(L_{0}\right)$.

Proof. By a substitution it is easy to check that $v_{0, r, k}(x) \in D\left(L_{0}\right), L_{0} v_{0, r, k}(x)=\lambda_{k} v_{0, r, k}(x)$, $k \in \mathbb{N}^{m}$.

Therefore, the operator $L_{0}$ has a system of eigenfunctions $V\left(L_{0}\right)$ which corresponds to the set of eigenvalues $\sigma\left(L_{0}\right):=\left\{\lambda_{k} \in \mathbb{R}, k \in \mathbb{N}^{m}\right\}$.

\section{NONSELFADJOINT PROBLEM OF ORDINARY DIFFERENTIAL EQUATION OF THE SECOND} ORDER

Let us consider the following spectral boundary problem

$$
\begin{aligned}
& -z^{(2)}\left(x_{j}\right)=\mu z\left(x_{j}\right), x_{j} \in\left\{0, X_{j}\right\}, \mu \in \mathbb{C}, \\
& z(0)+z\left(X_{j}\right)=0, z^{(1)}(0)+z^{(1)}\left(X_{j}\right)+b\left(z(1)(0)-z(1)\left(X_{j}\right)\right)=0 .
\end{aligned}
$$

Let $B_{j}=B_{j, b}$ be the operator of problem (8), (9). Solutions $\pm \rho$ of the characteristic equation $-\rho^{2}=\lambda$ are such that $\operatorname{Re} \mu \leq 0$.

We define the fundamental system of solutions of the equation (8) by equations

$$
z_{r}\left(x_{j}, \rho\right):=\exp \imath \rho x_{j}+(-1)^{r} \exp \imath \rho\left(X_{j}-x_{j}\right) \in L_{2, r}\left(0, X_{j}\right), r=0,1 .
$$

The general solution of equation (8) can be represented as the sum

$$
z\left(x_{j}, \rho\right):=c_{0} z_{0}\left(x_{j}, \rho\right)+c_{1} z_{1}\left(x_{j}, \rho\right) .
$$

If we substitute this solution into boundary conditions (9), we obtain an equation which roots define eigenvalues of the operator $B_{j}$

$$
\Delta(\rho):=\Delta_{0}(\rho) \Delta_{1}(\rho)=0,
$$

where $\Delta_{0}(\rho)=\left(1+\exp \imath \rho X_{j}\right), \Delta_{1}(\rho)=\imath \rho\left(1+\exp \imath \rho X_{j}\right)$.

Equation (10) has two-fold roots $\pm \rho_{k_{j}} \rho_{k_{j}}:=(2 k-1) \pi X_{j}^{-1}, k=1,2, \ldots$. Therefore the operator $B_{j}$ has two-fold eigenvalues $\mu_{k, j}=\left(\left(2 k_{j}-1\right) \pi X_{j}^{-1}\right)^{2}, k_{j}=1,2, \ldots$ Since $\tau_{2 k-1, j}\left(x_{j}\right) \in$ $D\left(B_{j}\right)$ and $B_{j} \tau_{2 k-1, j}\left(x_{j}\right)=\mu_{2 k-1, j} \tau_{2 k-1, j}\left(x_{j}\right), k_{j}=1,2, \ldots$, we define eigenfunction of the operator $B_{j}$ by the formula

$$
v_{1, k}\left(x_{j}, B_{j}\right)=\frac{2}{\sqrt{2 X_{j}}} \cos \rho_{k, j} x_{j}, k=1,2, \ldots
$$


We define an adjoint function of the operator $B_{j}$ by the following relation

$$
v_{0, k}\left(x_{j}, B_{j}\right)=\left(1+c_{j}\left(2 x_{j}-X_{j}\right)\right) \frac{2}{\sqrt{2 X_{j}}} \sin \rho_{k_{j}} x_{j}, c_{j} \in \mathbb{C} .
$$

If we substitute this expression to boundary condition (9) we define $c_{j}=b$.

So the operator $B_{j}$ has an adjoint function

$$
v_{0, k}\left(x_{j}, B_{j}\right)=\left(1+b\left(2 x_{j}-X_{j}\right)\right) \frac{2}{\sqrt{2 X_{j}}} \sin \rho_{k_{j}} x_{j} .
$$

Root functions of the operator $B_{j}$ are defined by equations

$$
\begin{aligned}
& B_{j} v_{0, k}\left(x_{j}, B_{j}\right)=\mu_{k, j} v_{0, k}\left(x_{j}, B_{j}\right)+\xi_{k, j} v_{1, k}\left(x_{j}, B_{j}\right), \xi_{k, j}=4 b \rho_{k, j}, k_{j}=1,2, \ldots, \\
& B_{j} v_{2 k-1}\left(x_{j}, A B_{j}\right)=\mu_{k, j} v_{2 k-1}\left(x_{j}, B_{j}\right), k=1,2, \ldots
\end{aligned}
$$

Since the boundary conditions (9) are regular by Birkhoff, from Shkalikov's theorem [29] we obtain: the system $V\left(B_{j}\right)$ is total and minimal in the space $L_{2}\left(0, X_{j}\right)$ for all $b \in \mathbb{R}, j=1,2, \ldots, m$.

Let us prove that $V\left(B_{j}\right)$ is a Bessel system. Summands in the formula (11) are orthogonal in the space $L_{2}\left(0, X_{j}\right)$. Therefore for any function $h \in L_{2}\left(0, X_{j}\right)$ we have

$$
\begin{aligned}
& \mid\left(h, v_{0, k}\left(x_{j}, B_{j}\right) ;\left.L_{2}\left(0, X_{j}\right)\right|^{2} \leq\left(1+2|b|^{2} X_{j}\right)||\left(h, \tau_{2 k}\left(x_{j}\right) ;\left.L_{2}\left(0, X_{j}\right)\right|^{2},\right.\right. \\
& \mid\left(h, v_{1, k}\left(x_{j}, B_{j} ;\left.L_{2}\left(0, X_{j}\right)\right|^{2}=\mid\left(h, \tau_{2 k-1}\left(x_{j}\right) ;\left.L_{2}\left(0, X_{j}\right)\right|^{2} .\right.\right.\right.
\end{aligned}
$$

If we consider the sum for $k=1,2, \ldots$, we have inequality

$$
\sum_{r=0}^{1} \sum_{k=1}^{\infty} \mid\left(h, v_{r, k}\left(x_{j}, B_{j}\right) ;\left.L_{2}\left(0, X_{j}\right)\right|^{2} \leq C_{2}\left|h ; L_{2}\left(0, X_{j}\right)\right|^{2}, C_{2}=1+2|b|^{2} X_{j} .\right.
$$

Therefore $V\left(B_{j}\right)$ is the Bessel system [19] in the space $L_{2}\left(0, X_{j}\right)$.

Analogously we can prove that the biorthogonal system which consists of root functions of adjoint problem

$$
-z^{(2)}\left(x_{j}\right)=\bar{\mu} z\left(x_{j}\right), z^{(1)}(0)+z^{(1)}\left(X_{j}\right)=0, z(0)+z\left(X_{j}\right)+b\left(z(0)-z\left(X_{j}\right)\right)=0
$$

is Bessel system in the space $L_{2}\left(0, X_{j}\right)$. Therefore if we apply Bari's theorem [19] we obtain the following lemma.

Lemma 3. For any fixed $b_{j} \in \mathbb{R}$ spectra of operators $B_{j}, A_{0, j}$ coincide and system of functions $V\left(B_{j}\right)$ forms a Riesz basis in the space $L_{2}\left(0, X_{j}\right), j=1,2, \ldots, m$.

\section{TRANSFORMATION OPERATORS OF ORDINARY DIFFERENTIAL EQUATION OF SECOND} ORDER

Let us consider any sequence of real numbers $\left\{\theta_{k_{j}}\right\}_{k_{j}=1}^{\infty}$ and consider in the space $L_{2}\left(0, X_{j}\right)$ operator $A_{1, j}$. An eigenvalues of this operator coinside with eigenvalues of the operator $A_{0, j}$ and root functions can be defined by equations

$$
\begin{aligned}
& v_{1, k, j}\left(x_{j}, A_{1, j}\right)=\frac{2}{\sqrt{2 X_{j}}} \cos \rho_{k, j} X_{j}^{-1} x_{j}, \\
& v_{0, k, j}\left(x_{j}, A_{1, j}\right)=\left(1+\theta_{k_{j}}\left(2 x_{j}-1\right)\right) \frac{2}{\sqrt{2 X_{j}}} \sin \rho_{k, j} X_{j}^{-1} x_{j}, k_{j}=1,2, \ldots
\end{aligned}
$$

Let $R\left(A_{1, j}\right)=E_{j}+S\left(A_{1, j}\right)$ be the operator which acts by rule $V\left(A_{0, j}\right) \rightarrow V\left(A_{1, j}\right)$. From definition of the operator $R\left(A_{1, j}\right)$ we obtain: $S^{2}\left(A_{1, j}\right)=0$. Therefore $R^{-1}\left(A_{1, j}\right)=E_{j}-S\left(A_{1, j}\right)$ exists. 
Lemma 4. For any sequence $\left\{\theta_{k_{j}}\right\}_{k_{j}=1}^{\infty} \subset \mathbb{R}$ the system of functions $V\left(A_{1, j}\right)$ are total and minimal in the space $L_{2}\left(0, X_{j}\right)$.

Proof. Let us suppose that function $h=h_{0}+h_{1}, h_{r} \in L_{2, r}\left(0, X_{j}\right)$ exists and is orthogonal to all elements of the system $V\left(A_{1, j}\right)$. Since functions (14) are elements of orthnormal basis of the space $L_{2,1}\left(0, X_{j}\right)$, we obtain $h_{1}=0$ So $h=h_{0} \in L_{2,0}\left(0, X_{j}\right)$.

Since function $h$ is orthogonal to elements of the system $V\left(A_{1, j}\right)$, we have:

$$
\left(h, v_{0, k}\left(x_{j}, A_{1, j}\right) ; L_{2}\left(0, X_{j}\right)\right)=\left(h_{0}, \tau_{0, k, j}\left(x_{j}\right) ; L_{2}\left(0, X_{j}\right)\right)=0, k=1,2, \ldots
$$

The system $T_{j, 0}=\left\{\tau_{0, k, j}\left(x_{j}\right) \in L_{2}\left(0, X_{j}\right), k=1,2, \ldots\right\}$ is an orthonormal basis in the space $L_{2,0}\left(0, X_{j}\right)$. So we obtain that $h_{1}=0$.

Therefore $h \equiv 0$.

Lemma 5. The system of functions $V\left(A_{1, j}\right)$ is a Riesz basis in the space $L_{2}\left(0, X_{j}\right)$ if and only if the sequence $\left\{\theta_{k}\right\}_{k=1}^{\infty}$ is bounded.

Proof. Necessity. If the system of functions $V\left(A_{1, j}\right)$ is a Riesz basis in the space $L_{2}\left(0, X_{j}\right)$, then it is almost normalized.

If we take into consideration (14), (15), we have inequality

$$
0<1 \leq\left\|v_{0, q}\left(x_{j}, A_{1, j}\right) ; L_{2}\left(0, X_{j}\right)\right\|^{2}=1+\left|\theta_{q}\right|^{2} \leq C_{3}<\infty, C_{3}:=1+\max \theta_{q}^{2} .
$$

Sufficiency. If we take into consideration formulas (12), (13) then for any functions $h \in L_{2}\left(0, X_{j}\right)$ we have inequality

$$
\begin{aligned}
& \sum_{k_{j}=1}^{\infty} \sum_{s=0}^{1} \|\left(R\left(A_{1, j}^{*}\right) h, \tau_{s, k_{j}}\left(x_{j}\right) ; L_{2}\left(0, X_{j} \|^{2}\right.\right. \\
& =\sum_{k_{j}=1}^{\infty} \sum_{s=0}^{1}\left|\left(h, v_{s, k_{j}}\left(x_{j}, A_{1, j}\right) ; L_{2}\left(0, X_{j}\right)\right)\right|^{2} \leq C_{3}\left\|h ; L_{2}\left(0, X_{j}\right)\right\|^{2} .
\end{aligned}
$$

Therefore the operator $R\left(A_{1, j}^{*}\right)$ is adjoint to $R\left(A_{1, j}\right)$ and bounded in the space $L_{2}\left(0, X_{j}\right) \rightarrow$ $L_{2}\left(0, X_{j}\right)$. So operators $R\left(A_{1, j}\right), R^{-1}\left(A_{1, j}\right)=2 E-R\left(A_{1, j}\right)$ are also bounded.

If we take into consideration Lemma 4 and Bari's theorem [19] we get: the system of function $V\left(A_{1, j}\right)$ is a Riesz basis in the space $L_{2}\left(0, X_{j}\right)$.

\section{NONSELFADJOINT PROBLEM FOR ORDINARY DIFFERENTIAL EQUATION OF EVEN ORDER}

Let us consider for any $j \in\{1,2, \ldots, m\}, p \in\{1,2, \ldots, n\}, b \in \mathbb{R}$, the problem

$$
\begin{aligned}
& L(D) y:=\sum_{|\beta| \leq n} a_{\beta} D^{2 \beta} y=\lambda y, \lambda \in \mathbb{C}, \\
& \ell_{1, s, q} y:=\left.D_{q}^{2 s-2} y\right|_{x_{q}=0}+\left.D_{q}^{2 s-2} y\right|_{x_{q}=X_{q}}=0, q \neq j, s=1, \ldots, n, q=1, \ldots, m, \\
& \ell_{1, n+s, q} y:=\left.D_{q}^{2 s-1} y\right|_{x_{q}=0}+\left.D_{q}^{2 s-1} y\right|_{x_{q}=X_{q}}=0, s \neq p, q \neq j, q=1, \ldots, m, s=1, \ldots, n, \\
& \ell_{1, n+s, j} y:=\left.D_{j}^{2 s-2} y\right|_{x_{j}=0}+\left.D_{j}^{2 s-2} y\right|_{x_{j}=X_{j}}=0, s \neq p, s=1,2, \ldots, n, \\
& \ell_{1, n+s, j} y:=\left.D_{j}^{2 s-1} y\right|_{x_{j}=0}+\left.D_{j}^{2 s-1} y\right|_{x_{j}=X_{j}}=0, \\
& \ell_{1, n+p, j} y:=\left.D_{j}^{2 p-1} y\right|_{x_{j}=0}+\left.D_{j}^{2 p-1} y\right|_{x_{j}=X_{j}}+b\left(\left.D_{j}^{2 p-1} y\right|_{x_{j}=0}-\left.D_{j}^{2 p-1} y\right|_{x_{j}=X_{j}}\right)=0 .
\end{aligned}
$$


Let $L_{1, p, j}$ be an operator of the problem (16) - (21), $V\left(L_{1, p, j}\right)$ be the system of root functions of operator $L_{1, p, j}$. This operator acts in a following manner $L_{1, p, j} y:=L(D) y, y \in D\left(L_{1, p, j}\right)$, $D\left(L_{1, p, j}\right):=\left\{y \in W_{2}^{2 n}(G): \ell_{1, r, j} y=0, r=1,2, \ldots, 2 n, j=1,2, \ldots, m\right\}$.

Let us consider by fixing $k(j):=\left(k_{1}, k_{2}, \ldots, k_{j-1}, k_{j+1}, \ldots, k_{m}\right) \in \mathbb{N}^{m-1}$ solutions of the problem (16) - (21) in a form of product

$$
y(x):=z\left(x_{j}\right) \prod_{r=1, r \neq j}^{m} \tau_{q_{r}, k_{r}}\left(x_{r}\right), k_{r}=1,2, \ldots, j \neq r, r=1,2, \ldots, m .
$$

For determination of an unknown function $z\left(x_{j}\right)$ we have the following problem

$$
\begin{aligned}
& \sum_{|\beta| \leq n} a_{\beta}(-1)^{\beta_{r}} \prod_{r=1, r \neq j}^{m}(-1)^{\beta_{r}} \rho_{k, r}^{2 \beta_{r}} z^{\left(2 \beta_{j}\right)}\left(x_{j}\right)=\lambda z\left(x_{j}\right), \lambda \in \mathbb{C}, \\
& \ell_{1, s, j} z:=\left.z^{(2 s-2)}\right|_{x_{j}=0}+\left.z^{(2 s-2)}\right|_{x_{j}=X_{j}}=0, s=1,2, \ldots, n, \\
& \ell_{1, n+s, j} z:=\left.z^{(2 s-1)}\right|_{x_{j}=0}+\left.z^{(2 s-1)}\right|_{x_{j}=X_{j}}=0, s \neq p, s=1,2, \ldots, n, \\
& \ell_{1, n+p, j} z:=\left.z^{(2 p-1)}\right|_{x_{j}=0}+\left.z^{(2 p-1)}\right|_{x_{j}=X_{j}}+b\left(\left.z^{(2 p-1)}\right|_{x_{j}=0}-\left.z^{(2 p-1)}\right|_{x_{j}=X_{j}}\right)=0 .
\end{aligned}
$$

Let $L_{1, k(j)}$ be the operator of the broblem $(23)-(26)$. The operator $L_{0,\left(k_{j}\right)}$ is partial case of operator $L_{1, k(j)}$, if $b=0$.

So

$$
\begin{aligned}
& L_{1, k(j)} z\left(x_{j}\right):=\sum_{|\beta| \leq n} a_{\beta}(-1)^{\beta_{s}} \prod_{s=1, s \neq j}^{m}\left(\rho_{k, s}\right)^{2 \beta_{s}} z^{\left(2 \beta_{j}\right)}\left(x_{j}\right), z \in D\left(L_{1, k(j)}\right), \\
& D\left(L_{1, k(j)}\right):=\left\{y \in W_{2}^{2 n}\left(0, X_{j}\right): \ell_{1, s, j} z=0, s=1,2, \ldots, 2 n\right\} .
\end{aligned}
$$

Lemma 6. For any $a_{\beta} \in \mathbb{R},|\beta| \leq n, k(j) \in \mathbb{Z}_{0}^{m-1}, p \in\{1,2, \ldots, n\}, b \in \mathbb{R}$, the operator $L_{1, k(j)}$ has eigenvalues (5) and a system of root functions $V\left(L_{1, k(j)}\right)$, which is a Riesz basis in the space $L_{2}\left(0, X_{j}\right)$.

Proof. The root $\omega_{r}(k(j), \lambda)$ of the equation

$$
\sum_{|\beta| \leq n} a_{\beta} \prod_{s=1, s \neq j}^{m}\left(\rho_{k, s}\right)^{2 \beta_{s}} \omega^{2 \beta_{j}}=\lambda,
$$

which is characteristic for the equation (23), we will chose from the condition $\operatorname{Re} \omega_{n}(k(j), \lambda) \leq$ $\operatorname{Re} \omega_{n-1}(k(j), \lambda) \leq \ldots \leq \operatorname{Re} \omega_{1}(k(j), \lambda) \leq 0$.

Let us consider functions

$$
\begin{aligned}
& z_{0,1}\left(x_{j}, \lambda\right)=\left(2 x_{j}-X_{j}\right) \frac{2}{\sqrt{2 X_{j}}} \sin \omega_{1}(k(j), \lambda) X_{j}^{-1} x_{j}, \\
& z_{0, q}\left(x_{j}, \lambda\right):=\frac{1}{2}\left(1-e^{\omega_{q}(k(j), \lambda) X_{j}}\right)^{-1}\left(e^{\omega_{q}(k(j), \lambda) x_{j}}+e^{\omega_{q}(k(j), \lambda)\left(X_{j}-x_{j}\right)}\right) \in L_{2,0}\left(0, X_{j}\right), q=\overline{2, n}, \\
& \left.z_{0, n+1}\left(x_{j}, \lambda\right)=\left(2 x_{j}-X_{j}\right)\right) \frac{2}{\sqrt{2 X_{j}}} \cos \omega_{1}(k(j), \lambda) X_{j}^{-1} x_{j}, \\
& z_{0, n+q}\left(x_{j}, \lambda\right):=\frac{1}{2}\left(1+e^{\omega_{q}(k(j), \lambda) X_{j}}\right)^{-1}\left(e^{\omega_{q}(j, k(j), \lambda) x_{j}}-e^{\omega_{q}(k(j), \lambda)\left(X_{j}-x_{j}\right)}\right) \in L_{2,1}\left(0, X_{j}\right), q=\overline{2, n} .
\end{aligned}
$$


If we substitute this expressions in boundary conditions (24) - (26), we will get eigenvalues (5) and eigenfunctions of the operator $L_{1, k(j)}$

$$
v_{1, k_{j}}\left(x_{j}, L_{1, k(j)}\right)=\frac{2}{\sqrt{2 X_{j}}} \cos \rho_{k, j} X_{j}^{-1} x_{j}, k_{j}=1,2, \ldots
$$

Let $\omega_{r}\left(k_{j}, \lambda_{k}\right)$ are roots of the equation (27), $\lambda=\lambda_{k}$ obtained from the equation $\omega_{1}\left(k_{j}, \lambda_{k}\right)=$ $\imath \pi\left(2 k_{j}-1\right) X_{j}^{-1}$ and $\operatorname{Re} \omega_{n}\left(k_{j}, \lambda_{k}\right) \leq \operatorname{Re} \omega_{n-1}\left(k_{j}, \lambda_{k}\right) \leq \ldots \leq \operatorname{Re} \omega_{1}\left(k_{j}, \lambda_{k}\right) \leq 0$.

Let us consider system of functions

$$
\begin{aligned}
& \left.z_{0,1}\left(x_{j}, k_{j}, \lambda_{k}\right)=\left(2 x_{j}-X_{j}\right)\right) \frac{2}{\sqrt{2 X_{j}}} \sin \rho_{k, j} X_{j}^{-1} x_{j}, k_{j}=1,2, \ldots, \\
& z_{0, q}\left(x_{j}, k_{j}, \lambda_{k}\right):=\frac{1}{2}\left(1+e^{\omega_{q, k_{j}} \lambda_{k} X_{j}}\right)^{-1}\left(\left(e^{\omega_{q, k_{j}}\left(\lambda_{k}\right) x_{j}}-e^{\omega_{q, k_{j}}\left(\lambda_{k}\right)\left(X_{j}-x_{j}\right)}\right)\right), k_{j}=1,2, \ldots,
\end{aligned}
$$

and a square matrix of the order $n$, which elements we can define as follows: $p$-th row defined by functions (29), (30) and elements of other rows defined by numbers

$$
\begin{aligned}
& \eta_{q, r, k_{j}}=\left(\rho_{k, j}\right)^{1-2 r} \ell_{1, n+r, j} z_{1, q}\left(x_{j}, k_{j}, \lambda_{k}\right)=\left(\omega_{j}\left(k_{j}, \lambda_{k}\right) X_{j}\right)^{2 r-1}, \\
& \eta_{1, r, k_{j}}=(-1)^{r} \sqrt{2 X_{j}}, k_{j}=1,2, \ldots, q=2, \ldots, n, r \neq p, r=1,2, \ldots, n .
\end{aligned}
$$

Determinant of obtained matrix we will denote by $y_{1, p, k_{j}}\left(x_{j}, \lambda_{k}\right), k_{j}=1,2, \ldots$.

Remark 1. For any fixed $k(j) \in \mathbb{N}^{m-1}$, if $k_{j} \rightarrow \infty$, we get

$$
\begin{aligned}
& \delta_{1, k_{j}}\left(\lambda_{k}\right)=\omega_{1}\left(k_{j}, \lambda_{k}\right)\left(2 \pi k_{j} X_{j}^{-1}\right)^{-1}=\imath, \\
& \delta_{q, k_{j}}\left(\lambda_{k}\right)=\omega_{q}\left(k_{j}, \lambda_{k}\right)\left(2 \pi k_{j} X_{j}^{-1}\right)^{-1}=\varepsilon_{q} X_{j}\left(1+O\left(k_{j}^{-1}\right)\right),
\end{aligned}
$$

where $\varepsilon_{q}$ are roots of the equation $(-1)^{n}(\varepsilon)^{2 n}=1, \operatorname{Im} \varepsilon_{q}<0, q=2,3, \ldots, n$. ities

If we substitute function $y_{1, p, k_{j}}\left(x_{j}, \lambda_{k}\right)$ in boundary conditions (23) - (26), we will get equal-

$$
\begin{aligned}
& \ell_{1, s, j} y_{1, p, k_{j}}=0, j \neq n+p, k_{j}=1,2, \ldots, \\
& c_{p, k_{j}}:=\ell_{1, n+p, j} y_{1, p, k_{j}}=\sqrt{2 X_{j}} \rho_{k_{j}}^{2 p-1} W_{k_{j}}\left(\lambda_{k}\right) \prod_{q=1}^{n} \delta_{q, k_{j}}\left(\lambda_{k}\right), k_{j}=1,2, \ldots,
\end{aligned}
$$

where $W_{k_{j}}\left(\lambda_{k}\right)$ is a Wandermond determinant of the order $n$, which is constructed by numbers $-1, \delta_{q, k_{j}}\left(\lambda_{k}\right)^{2}, q=2,3, \ldots, n$.

Remark 2. For any fixed $k(j) \in \mathbb{N}^{m-1}$ number sequence $W_{k_{j}, n}\left(\lambda_{k}\right)$ converges to Wandermond determinant $W\left(\varepsilon_{2}^{2}, \ldots, \varepsilon_{n}^{2}\right)$, if $k_{j} \rightarrow \infty$, which is constructed using numbers $\varepsilon_{2}^{2}, \ldots, \varepsilon_{n}^{2}$.

Under this conditions sequence $\delta_{q, k_{j}}\left(\lambda_{k}\right)$ converges to $\varepsilon_{q}, q=1,2, \ldots, n$.

Then there exist positive numbers $C_{4}, C_{5}$ such that following inequality takes place:

$$
0<C_{4} \leq\left|c_{p, k_{j}}\right|^{-1} \rho_{k_{j}}^{1-2 p} \leq C_{5}<\infty, k_{j}=1,2, \ldots
$$

Let us choose function $y_{2, p, k_{j}}\left(x_{j}, \lambda_{k}\right)$ so that the equality

$$
\ell_{1, n+p, j} y_{2, p}\left(x_{j}, k_{j}, \lambda_{k}\right)=\left(\sqrt{2 X_{j}}\right)^{-1} \rho_{k_{j}}^{2 p-1}
$$


takes place. An adjoint function $v_{0, k_{j}}\left(x_{j}, L_{1,\left(k_{j}\right.}\right)$ of the operator $L_{1,\left(k_{j}\right)}$ we define by sum

$$
v_{0, k_{j}}\left(x_{j}, L_{1,\left(k_{j}\right)}\right):=\frac{2}{\sqrt{2 X_{j}}} \sin \left(2 k_{j}-1\right) \pi X_{j}^{-1} x_{j}+\eta_{1, p, j, k} y_{2, p, k_{j}}\left(x_{j}, \lambda_{k}\right), k_{j}=1,2, \ldots
$$

To define unknown parameters $\eta_{1, p, j, k}$ we substitute expression (35) in boundary conditions (25), (26). If we consider formula (34), we obtain

$$
\eta_{1, p, j, k}=(-1)^{p} b, k_{j}=1,2, \ldots
$$

Remark 3. Functions $y_{1, p, k_{j}}\left(x_{j}, \lambda_{k}\right)$ and $y_{2, p, k_{j}}\left(x_{j}, \lambda_{k}\right)$ connected with notions

$$
y_{2, p, k_{j}}\left(x_{j}, \lambda_{k}\right)=\chi_{p, j, k} y_{1, p, k_{j}}\left(x_{j}, \lambda_{k}\right) \text {, }
$$

where $C_{6} \leq\left|\chi_{p, j, k}\right| \leq C_{7}, p=1,2, \ldots, n, j=1,2, \ldots, m, k \in \mathbb{N}^{m}$.

Therefore operator $L_{1,\left(k_{j}\right)}$ has a system $V\left(L_{1,\left(k_{j}\right)}\right)$ of root functions (29), (35), (36) in sense of equations

$$
\begin{aligned}
& L_{1,\left(k_{j}\right)} v_{0, k_{j}}\left(x_{j}, L_{1,\left(k_{j}\right)}\right)=\lambda_{k} v_{0, k_{j}}\left(x_{j}, L_{1,\left(k_{j}\right)}\right)+\xi_{p, k_{j}} v_{1, k_{j}}\left(x_{j}, L_{1,\left(k_{j}\right)}\right), \\
& \xi_{p, k_{j}}:=\operatorname{det}\left(\eta_{q, r, k_{j}}\right)_{r=\overline{1, n}, r \neq p}^{q=\overline{2, n}} \frac{\partial \lambda_{k}}{\partial \rho_{j, k}} \chi_{p, j, k} \eta_{1, p, j, k} c_{p, k_{j}}, p=1,2, \ldots, n, j=1,2, \ldots, m, k \in \mathbb{N}^{m} .
\end{aligned}
$$

For problem (21) - (26) there exists an adjoint problem which has a system of root functions that is biorthogonal to $V\left(L_{1,\left(k_{j}\right)}\right)$. Therefore the system $V\left(L_{1,\left(k_{j}\right)}\right)$ is total and minimal in the space $L_{2}\left(0, X_{j}\right)$.

Let $H_{p,\left(k_{j}\right)}$ be a root subspace of the operator $V\left(L_{1,\left(k_{j}\right)}\right)$ which corresponds to two-fold eigenvalue $\lambda_{k}$. According to the Shkalikov theorem [29] the system of subspaces $\left\{H_{p,\left(k_{j}\right)}\right\}_{k_{j}=1}^{\infty}$ is a Riesz basis of subspaces.

Let $y_{3, p, k_{j}}\left(x_{j}, \lambda_{k}\right):=v_{0, k_{j}}\left(x_{j}, L_{1,\left(k_{j}\right.}\right)-\left(v_{0, k_{j}}, v_{1, k_{j}} ; L_{2}\left(0, X_{j}\right)\right) v_{1, k_{j}}\left(x_{j}, L_{1,\left(k_{j}\right)}\right)$. Let us notice that functions $y_{3, p, k_{j}}\left(x_{j}, \lambda_{k}\right)$ and $v_{1, k_{j}}\left(x_{j}, L_{1,\left(k_{j}\right)}\right)$ are orthogonal in the space $L_{2}\left(0, X_{j}\right)$. Let

$$
y_{4, p, k_{j}}\left(x_{j}, \lambda_{k}\right):=\varphi_{p, k_{j}} y_{3, p, k_{j}}\left(x_{j}, \lambda_{k}\right),
$$

where $\varphi_{p, k_{j}}$ satisfy condition $\left\|y_{4, p, k_{j}}\left(x_{j}, \lambda_{k}\right) ; L_{2}\left(0, X_{j}\right)\right\|=1$. Therefore functions $y_{4, p, k_{j}}\left(x_{j}, \lambda_{k}\right)$ and $v_{1, k_{j}}\left(x_{j}, L_{1,\left(k_{j}\right)}\right)$ form an orthonormal basis in the space $H_{p,\left(k_{j}\right)}$. Since (17) takes place we obtain following: system of functions $\left.\left\{v_{1, k_{j}}\left(x_{j}, L_{1,\left(k_{j}\right)}\right) y_{4, p_{k}, k_{j}\left(x_{j},\right.} \lambda_{k}\right)\right\}_{k_{j}=1}^{\infty}$ is a Riesz basis in the space $L_{2}\left(0, X_{j}\right)$.

Therefore such positive numbers $C_{8}, C_{9}$ exist that for any function $\varphi \in L_{2}\left(0, X_{j}\right)$ inequality

$$
C_{8}\left\|\varphi ; L_{2}\left(0, X_{j}\right)\right\|^{2} \leq \sum_{k_{j}=1}^{\infty}\left(\left(\varphi, v_{1, k_{j}} ; L_{2}\left(0, X_{j}\right)\right)^{2}+\left(\varphi, y_{4, p, k_{j}} ; L_{2}\left(0, X_{j}\right)\right)^{2} \leq C_{9}\left\|\varphi ; L_{2}\left(0, X_{j}\right)\right\|^{2}\right.
$$

takes place. If we consider equation (38) and inequality $1<\varphi_{p, k_{j}}<\infty$ for any function $\varphi \in$ $L_{2}\left(0, X_{j}\right)$, we obtain the following estimation

$$
C_{10}\left\|\varphi ; L_{2}\left(0, X_{j}\right)\right\|^{2} \leq \sum_{k_{j}=1}^{\infty}\left(\left(\varphi, v_{1, k_{j}} ; L_{2}\left(0, X_{j}\right)\right)^{2}+\left(\varphi, y_{3, p, k_{j}} ; L_{2}\left(0, X_{j}\right)\right)^{2} \leq C_{11}\left\|\varphi ; L_{2}\left(0, X_{j}\right)\right\|^{2} .\right.
$$


Let us prove that the system of functions $V\left(L_{1,\left(k_{j}\right)}\right)$ is Bessel in the space $L_{2}\left(0, X_{j}\right)$, so there exists a positive number $C_{12}$ such that following inequality

$$
\sum_{k_{j}=1}^{\infty}\left(\left(\varphi, v_{0, k_{j}} ; L_{2}\left(0, X_{j}\right)\right)^{2}+\left(\varphi, v_{1, k_{j}} ; L_{2}\left(0, X_{j}\right)\right)^{2} \leq C_{12}\left\|\varphi ; L_{2}\left(0, X_{j}\right)\right\|^{2}\right.
$$

takes place. From the Cauchy inequality and the definition of $y_{3, p, k_{j}}$ we have the following estimation

$$
\left(\varphi, v_{0, k_{j}} ; L_{2}\left(0, X_{j}\right)\right)^{2} \leq 2\left(\left(\varphi, y_{3, p, k_{j}} ; L_{2}\left(0, X_{j}\right)\right)^{2}+\left(\varphi, v_{1, k_{j}} ; L_{2}\left(0, X_{j}\right)\right)^{2}\right)\left(v_{0, k_{j}}, v_{1, k_{j}} ; L_{2}\left(0, X_{j}\right)\right)^{2} .
$$

The system of functions $V\left(L_{1,\left(k_{j}\right)}\right)$ is orthonormal in the space $L_{2}\left(0, X_{j}\right)$. Then inequality $\left|\left(v_{0, k_{j}}, v_{1, k_{j}} ; L_{2}\left(0, X_{j}\right)\right)\right|^{2} \leq C_{13}<\infty$ takes place. If we consider the last inequality and (38) we will get (40) if $C_{12}=3 C_{9}+2 C_{13}$.

Let $R\left(L_{1, k(j)}\right):=E_{j}+S\left(L_{1, k(j)}\right): L_{2}\left(0, X_{j}\right) \rightarrow L_{2}\left(0, X_{j}\right)$ be an operator that acts $V\left(A_{0, j}\right) \rightarrow$ $V\left(L_{1, k(j)}\right)$. If we consider operator $S\left(L_{1, k(j)}\right): L_{2,0}\left(0, X_{j}\right) \rightarrow L_{2,1}\left(0, X_{j}\right)$ for $L_{2,1}\left(0, X_{j}\right) \rightarrow 0$, we will obtain $S\left(L_{1, k(j)}\right)^{2}=0$. Therefore $R^{-1}\left(L_{1, k(j)}\right)=E_{j}-S\left(L_{1, k(j)}\right)$ exists.

Operator $R\left(L_{1, k(j)}\right):=E_{j}+S\left(L_{1, k(j)}\right): L_{2}\left(0, X_{j}\right) \rightarrow L_{2}\left(0, X_{j}\right)$ is bounded since the system is Bessel. Therefore the operator $R^{-1}\left(L_{1, k(j)}\right): L_{2}\left(0, X_{j}\right) \rightarrow L_{2}\left(0, X_{j}\right)$ is also bounded. Therefore the system of functions $V\left(L_{1,\left(k_{j}\right)}\right)$ is a Riesz basis in the space $L_{2}\left(0, X_{j}\right)$.

\section{TRANSFORMATION OPERATORS FOR DIFFERENTIAL EQUATIONS OF EVEN ORDER}

Let us consider a sequence $\left\{\theta_{k_{j}}\right\}_{k_{j}=1}^{\infty} \subset \mathbb{R}$ and consider an operator $A_{2, p, j}$ such that its eigenvalues coincide with eigenvalues of operator $A_{0, j}$ and root functions are defined by equations

$$
\begin{aligned}
& v_{1, k_{j}}\left(x_{j}, A_{2, p, j}\right)=\frac{2}{\sqrt{2 X_{j}}} \cos \rho_{k, j} x_{j}, \\
& v_{0, k_{j}}\left(x_{j}, A_{2, p, j}\right)=\frac{2}{\sqrt{2 X_{j}}} \sin \rho_{k, j} x_{j}+\theta_{k_{j}} y_{1, p, k_{j}}\left(x_{j}, \lambda_{k}\right), k_{j}=1,2, \ldots
\end{aligned}
$$

Let $R\left(A_{2, p, j}\right)=E+S\left(A_{2, p, j}\right)$ be an operator in the space $L_{2}\left(0, X_{j}\right)$ defined by $V\left(A_{0, j}\right) \rightarrow$ $V\left(A_{2, p, j}\right)$. From the definition of the operator $R\left(A_{2, p, j}\right)$ we obtain $S^{2}\left(A_{2, p, j}\right)=0$. Therefore, the operator $R^{-1}\left(A_{2, p, j}\right)=E-S\left(A_{2, p, j}\right)$ exists.

Lemma 7. For any $a_{\beta} \in \mathbb{R},|\beta| \leq n, j \in\{1,2, \ldots, m\}, k(j) \in \mathbb{N}^{m-1}$ and for any sequence $\left\{\theta_{k_{j}}\right\}_{k_{j}=1}^{\infty} \subset \mathbb{R}$ a system of functions $V\left(A_{2, p, j}\right)$ is total and minimal in the space $L_{2}\left(0, X_{j}\right)$. The system of functions $V\left(A_{2, p, j}\right)$ is a Riesz basis in the space $L_{2}\left(0, X_{j}\right)$ if and only if the sequence $\left\{\theta_{k_{j}}\right\}_{k_{j}=1}^{\infty}$ is bounded.

Proof. First part can be proved analogously to Lemma 4.

We will denote by $\Phi_{p}\left(L_{0,\left(k_{j}\right)}\right)$ a set of all operators $A_{2, p, j}$ defined by (41), (42). Also we denote by $\Gamma_{p}\left(L_{0,\left(k_{j}\right)}\right)$ a set of all operators $R\left(A_{2, p, j}\right)$, which are generated by operators $A_{2, p, j} \in$ $\Phi\left(L_{0,\left(k_{j}\right)}\right)$. From formula (35) we obtain $R\left(L_{1, k(j)}\right):=E_{j}+S\left(L_{1, k(j)}\right) \in \Gamma_{p}\left(L_{0,\left(k_{j}\right)}\right)$. Let us consider two sequences $\left\{\theta_{k_{j}}^{1}\right\}_{k_{j}=1}^{\infty},\left\{\theta_{k_{j}}^{2}\right\}_{k_{j}=1}^{\infty}$ and define two transformation operators $R_{q}=$ 
$E_{j}+S_{q} \in \Gamma_{p}\left(L_{0,\left(k_{j}\right)}\right), q=1,2$. Let us consider equality $S_{q}^{2}=0, q=1,2$, we can define $\Gamma_{p}\left(L_{0,\left(k_{j}\right)}\right)$ an operation of multiplication on the space

$$
R_{1} R_{2}=E_{j}+S_{1}+S_{2}
$$

From $R_{q}^{-1}=E_{j}-S_{q}$ it follows that the set $\Gamma_{p}\left(A_{0, j}\right)$ is a group. Since the equality $R_{1} R_{2}=$ $E_{j}+S_{1}+S_{2}=R_{2} R_{1}$ takes place we obtain that the set $\Gamma_{p}\left(L_{0,\left(k_{j}\right)}\right)$ is a commutative group.

Lemma 8. For any fixed $a_{\beta} \in \mathbb{R},|\beta| \leq n, j=1,2, \ldots, m, k(j) \in \mathbb{N}^{m-1}$ the system of functions $V\left(A_{2, p, j}\right)$ is a Riesz basis in the space $L_{2}\left(0, X_{j}\right)$ if and only if the sequence $\left\{\theta_{k_{j}}\right\}_{k_{j}=1}^{\infty}$ is bounded.

This lemma can be proved analogously to Lemma 7.

Let us choose an arbitrary $n$ sequences of real numbers $\left\{\theta_{p, k_{j}}\right\}_{k_{j}=1}^{\infty}, p=1,2, \ldots, m$, and consider an operator $A_{3, j}$. This operator eigenvalues coincides with eigenvalues of $A_{0, j}$ and roots of the function are defined by equations

$$
\begin{aligned}
& v_{1, k_{j}}\left(x_{j}, A_{3, j}\right)=\frac{2}{\sqrt{2 X_{j}}} \cos \rho_{k, j} x_{j}, \\
& v_{0, k_{j}}\left(x_{j}, A_{3, j}\right)=\frac{2}{\sqrt{2 X_{j}}} \sin \rho_{k, j} x_{j}+\sum_{p=1}^{n} \theta_{p, k_{j}} y_{1, p, k_{j}}\left(x_{j}, \lambda_{k}\right), k_{j}=1,2, \ldots
\end{aligned}
$$

Let $R\left(A_{3, j}\right)=E+S\left(A_{3, j}\right)$ be the operator defined in the space $L_{2}\left(0, X_{j}\right)$ by $V\left(A_{0, j}\right) \rightarrow$ $V\left(A_{3, j}\right)$. From the definition of $R\left(A_{3, j}\right)$ we obtain $S^{2}\left(A_{3, j}\right)=0$. Therefore operator $R^{-1}\left(A_{3, j}\right)=$ $E-S\left(A_{3, j}\right)$ exists.

Lemma 9. For any $a_{\beta} \in \mathbb{R},|\beta| \leq n$ and sequences $\left\{\theta_{p, k_{j}}\right\}_{k_{j}=1}^{\infty} \subset \mathbb{R}, p=1,2, \ldots, m$ a system of functions $V\left(A_{3, j}\right)$ is total and minimal in the space $L_{2}\left(0, X_{j}\right)$. The system of functions $V\left(A_{3, j}\right)$ is a Riesz basis in the space $L_{2}\left(0, X_{j}\right)$ if and only if any sequence $\left\{\theta_{p, k_{j}}\right\}_{k_{j}=1}^{\infty}, p=1,2, \ldots, m$ is bounded.

We can prove this lemma analogously to Lemma 7.

Let us define root functions of the operator $L_{1, p, j}$ by equalities

$$
v_{k}\left(x, L_{1, p, j}\right)=v_{k_{j}}\left(x_{j}, L_{1, k(j)}\right) \prod_{r=1, r \neq j}^{m} \tau_{r, k_{r}}\left(x_{r}\right), k \in \mathbb{N}^{m} .
$$

By the system $V\left(L_{1, p, j}\right)$ of root functions of the operator $L_{1, p, j}$ we define operator $R\left(L_{1, p, j}\right):=$ $E+S\left(L_{1, p, j}\right)$, which acts in the space $L_{2}(G)$. This operator transfer system of functions $V\left(L_{0}\right)$ to the system $V\left(L_{1, p, j}\right)$. So we obtain $R\left(L_{1, p, j} v_{k}\left(x,\left(L_{0}\right)\right):=v_{k}\left(x, L_{1, p, j}\right), k \in \mathbb{N}^{m}\right.$. The operator $R\left(L_{1, p, j}\right)$ is defined by equality

$$
R\left(L_{1, p, j}\right)=E_{1} \otimes \cdots \otimes E_{j-1} \otimes R\left(L_{1, k(j)}\right) \otimes E_{j+1} \ldots E_{m},
$$

where $E_{s}$ is the identical transformation in the space $L_{2}\left(0, X_{s}\right), s=1,2, \ldots, m$.

Let us denote by $\Gamma_{p, j}\left(L_{0}\right)$ a set of the operators which is defined by formula $E_{1} \otimes \cdots \otimes$ $E_{j-1} \otimes R\left(A_{2, p, j}\right) \otimes E_{j+1} \cdots \otimes E_{m}$, where $R\left(A_{2, p, j}\right) \in \Gamma(k(j))$. A set of the operators $R\left(L_{0}\right)=$ $R_{1} \otimes R_{2} \cdots \otimes R_{m}$ we will denote by $\Gamma_{p}\left(L_{0}\right)$. 
Remark 4. We define multiplication on the set $\Gamma_{p}\left(L_{0}\right)$ according to formula (43) such that this set will be abelian group.

Theorem 4. Let assumption $P_{1}$ takes place. Then for any fixed $a_{\beta} \in \mathbb{R},|\beta| \leq n$ an operator $L_{1, p, j}$ has eigenvalues (5) and system of root functions $V\left(L_{1, p, j}\right)$, which is total and minimal in the space $L_{2}(G)$.

If assumptions $P_{2}, P_{3}$ take place then the system of functions $V\left(L_{1, p, j}\right)$ is a Riesz basis in the space $L_{2}(G)$.

Proof. According to Lemma 6 for any $k(j) \in \mathbb{N}^{m-1}$ there exists a system of functions $W\left(L_{1, k(j)}\right)=\left\{w_{k_{j}}\left(x_{j}, L_{1, k(j)}\right), k_{j}=1,2, \ldots\right\}$, which is biorthogonal to the system $V\left(L_{1, k(j)}\right)$.

Therefore we can define elements of the system $W\left(L_{1, p, j}\right)$, which is biorthogonal in the space $L_{2}(G)$ to the system by $V\left(L_{1, p, j}\right)$

$$
w_{k}\left(x, L_{1, p, j}\right)=w_{k_{j}}\left(x_{j}, L_{1, k(j)}\right) \prod_{r=1, r \neq j}^{m} \tau_{r, k_{r}}\left(x_{r}\right), k \in \mathbb{N}^{m} .
$$

So the system $V\left(L_{1, p, j}\right)$ is total and minimal in the space $L_{2}(G)$. If assumptions $P_{2}, P_{3}$ take place then root functions (44) of the operator $L_{1, p, j}$ are normalized for any $k(j) \in \mathbb{N}^{m-1}$ and a system $V\left(L_{1, p, j}\right)$ is a Riesz basis of the space $L_{2}(G)$.

\section{PeRTURBATED BOUNDARY PROBLEM WITH ACCENTED VARIABLE}

Let us consider for any fixed $j=1,2, \ldots, m, p=1,2, \ldots, n$ equation (16) and problem with boundary conditions

$$
\begin{aligned}
& \ell_{2, s, r} y:=\left.D_{r}^{2 s-2} y\right|_{x_{r}=0}+\left.D_{r}^{2 s-2} y\right|_{x_{r}=X_{r}}=0, r \neq j, s=1,2, \ldots, n, r=1,2, \ldots, m, \\
& \ell_{2, n+s, r} y:=\left.D_{r}^{2 s-1} y\right|_{x_{r}=0}+\left.D_{r}^{2 s-1} y\right|_{x_{r}=X_{r}}=0, j \neq r, s=1,2, \ldots, n, r=1,2, \ldots, m, \\
& \ell_{2, n+p, j} y:=\left.D_{j}^{2 p-1} y\right|_{x_{j}=0}+\left.D_{j}^{2 p-1} y\right|_{x_{j}=X_{j}}+\left.\sum_{r=0}^{1} \sum_{q=0}^{m_{p, j}} b_{q, r, p, j} D_{j}^{q} y\right|_{x_{j}=r X_{j}}=0 .
\end{aligned}
$$

Let $L_{2, p, j}$ be the operator of the problem (16), (47) - (49), $L_{2, p, j} y:=L(D) y, y \in D\left(L_{2, p, j}\right)$, $D\left(L_{2}\right):=\left\{y \in W_{2}^{2 n}(G): \ell_{2, s, j} y=0, s=1,2, \ldots, 2 n, j=1,2, \ldots, m\right\}$. Let $V\left(L_{2}\right)$ be the system of root functions of $L_{2}$.

Consider for any fixed $k(j) \in \mathbb{N}^{m-1}$ solutions of the spectral problem for operator $L_{2}$ in a form of product (22). To define unknown function $z\left(x_{j}\right)$ we obtain the following problem

$$
\begin{aligned}
& \sum_{|\beta| \leq n}(-1)^{\beta_{j}} a_{\beta} \prod_{s=1, s \neq j}^{m} \mu_{k, s}^{\beta_{s}} z^{\left(2 \beta_{j}\right)}\left(x_{j}\right)=\lambda z\left(x_{j}\right), \lambda \in \mathbb{C}, \\
& \ell_{2, s, j} z:=\left.z^{(2 s-2)}\right|_{x_{j}=0}+\left.z^{(2 s-2)}\right|_{x_{j}=X_{j}}=0, s=1,2, \ldots, n, \\
& \ell_{2, n+s, r} z:=\left.z^{(2 s-1)}\right|_{x_{j}=0}+\left.z^{(2 s-1)}\right|_{x_{j}=X_{j}}=0, s \neq p, s=1,2, \ldots, n, \\
& \ell_{2, n+p, j} z:=\left.z^{(2 p-1)}\right|_{x_{j}=0}+\left.z^{(2 p-1)}\right|_{x_{j}=X_{j}}+\left.\sum_{r=0}^{1} \sum_{q=0}^{m_{p, j}} b_{q, r, p, j} z^{(q)}\right|_{x_{j}=r X_{j}}=0 .
\end{aligned}
$$


Let $L_{2, k(j)}$ be an operator of the problem (50) - (53). Therefore,

$$
\begin{aligned}
& L_{2, k(j)} z:=\sum_{|\beta| \leq n}(-1)^{\beta_{j}} a_{\beta} \prod_{s=1, s \neq j}^{m} \mu_{k, s}^{\beta_{s}} z^{\left(2 \beta_{j}\right)}\left(x_{j}\right), z \in D\left(L_{2, k(j)}\right), \\
& D\left(L_{2, k(j)}\right):=\left\{y \in W_{2}^{2 n}\left(0, X_{j}\right): \ell_{2, s, j} z=0, s=1,2, \ldots, 2 n\right\} .
\end{aligned}
$$

Lemma 10. Let assumption $P_{1}$ holds true. Then for any $a_{\beta} \in \mathbb{R}, b_{q, 0, p, j} \in \mathbb{R},|\beta| \leq n, q=$ $0,1, \ldots, m_{p, j}, k(j) \in \mathbb{N}^{m-1}$ operator $L_{2, k(j)}$ has eigenvalues (5) and a system of root functions $V\left(L_{2, k(j)}\right)$, which is total and minimal in the space $L_{2}\left(0, X_{j}\right)$.

If assumtion $P_{2}$ holds true then the system of functions $V\left(L_{2, k(j)}\right)$ is a Riesz basis in the space $L_{2}\left(0, X_{j}\right)$.

Proof. The isospectrality of operators $L_{0,\left(k_{j}\right)}$ and $L_{2, k(j)}$ can be proved by the same way as in Theorem 9.

If assumtion $P_{1}$ holds true, then eigenfunctions of the operator $L_{2, k(j)}$ are following

$$
v_{1, k_{j}}\left(x_{j}, L_{2, k(j)}\right)=\frac{2}{\sqrt{2 X_{j}}} \cos \rho_{k_{j}} X_{j}^{-1} x_{j}, k_{j}=1,2, \ldots
$$

Root functions $v_{0, k_{j}}\left(x_{j}, L_{2,\left(k_{j}\right)}\right)$ of the operator $L_{2,\left(k_{j}\right)}$ are defined by

$$
v_{0, k_{j}}\left(x_{j}, L_{2,\left(k_{j}\right)}\right)=\frac{2}{\sqrt{2 X_{j}}} \sin \rho_{k_{j}} X_{j}^{-1} x_{j}+\eta_{2, p, j, k} y_{1, p, k_{j}}\left(x_{j}, \lambda_{k}\right), k_{j}=1,2, \ldots
$$

To define $\eta_{2, p, j, k}$ we can substitute expression (55) into boundary conditions (51)-(53). If we consider formulas (32), (33) we obtain

$$
\eta_{2, p, j, k}=\left(c_{p, k_{j}}\right)^{-1} \ell_{p, j}^{2} \tau_{2 k_{j}-1, j}\left(x_{j}\right), k_{j}=1,2, \ldots
$$

Therefore, operator $L_{2, k(j)}$ has a system of eigenfunction (54) - (56). If we consider formulas (31), (32) we obtain that the operator $L_{2,\left(k_{j}\right)}$ is a partial case of the operator $A_{2, p, j}$. Therefore, from Lemma 7 it follows that the system $V\left(L_{2, k(j)}\right)$ is total and minimal in the space $L_{2}\left(0, X_{j}\right)$.

Let assumption $P_{1}$ holds. Since equations (33), (49) take place, we get $\left|\eta_{2, p, j, k}\right| \rho_{k, j}^{2 p-m_{p, j}-1} \leq$ $C_{14}<\infty$. So from Theorem 9 it follows that the system $V\left(L_{2, k(j)}\right)$ is a Riesz basis in the space $L_{2}\left(0, X_{j}\right)$.

Let us define root functions of the operator $L_{2, p, j}$ by equalities

$$
v_{k}\left(x, L_{2, p, j}\right)=v_{k_{j}}\left(x_{j}, L_{2, k(j)}\right) \prod_{r=1, r \neq j}^{m} \tau_{r, k_{r}}\left(x_{r}\right), k \in \mathbb{N}^{m} \text {. }
$$

Using the system $V\left(L_{2, p, j}\right)$ of root functions (57) of the operator $L_{2, p, j}$ we can define an operator $R\left(L_{2, p, j}\right):=E+S\left(L_{2, p, j}\right)$, which acts from system of functions $V\left(L_{0}\right)$ to the system $V\left(L_{2, p, j}\right)$. The operator $R\left(L_{2, p, j}\right)$ can be defined by equation (46). If assumption $P_{1}$ holds true, then for any $k(j) \in \mathbb{N}^{m-1}$ there exists a system of functions $W\left(L_{2, k(j)}\right)=\left\{w_{k_{j}}\left(x_{j}, L_{2, k(j)}\right), k_{j}=1,2, \ldots\right\}$, which is biorthogonal to the system $W\left(L_{2, k(j)}\right)$. 
Therefore, we can define elements of the biorthogonal system $W\left(L_{2, p, j}\right)$ in the space $L_{2}(G)$ to the system $V\left(L_{2, p, j}\right)$ by equality

$$
w_{k}\left(x, L_{2, p, j}\right)=w_{k_{j}}\left(x_{j}, L_{2, k(j)}\right) \prod_{r=1, r \neq j}^{m} \tau_{r, k_{r}}\left(x_{r}\right), k \in \mathbb{N}^{m} .
$$

So the system of functions $V\left(L_{2, p, j}\right)$ is total and minimal in the space $L_{2}(G)$.

If assumptions $P_{1}-P_{3}$ take place then system of functions $V\left(L_{2, p, j}\right)$ is Bessel in the space $L_{2}(G)$, since the transformation operator $R\left(L_{2, p, j}\right)$ is continuous with action $L_{2}(G) \rightarrow L_{2}(G)$. A converse operator is also bounded. Therefore the system of functions $V\left(L_{2, p, j}\right)$ is a Riesz basis of the space $L_{2}(G)$. So we prove following theorem.

Theorem 5. Let assumptions $P_{1}-P_{2}$ take place. Then for any fixed $a_{\beta} \in \mathbb{R}, b_{q, 0, p, j} \in \mathbb{R},|\beta| \leq$ $n$ operator $L_{2, p, j}$ has eigenvalues (5) a system of root functions $V\left(L_{2, p, j}\right)$, which is total and minimal in the space $L_{2}(G)$.

2. If assumptions $P_{1}-P_{3}$ take place, then system of functions $V\left(L_{2, p, j}\right)$ is Riesz basis in the space $L_{2}(G)$.

Consider boundary problem

$$
\begin{aligned}
& L(D) y:=\sum_{|\beta| \leq n} a_{\beta} D^{2 \beta} y=\lambda y, \\
& \ell_{3, s, r} y:=\left.D_{r}^{2 s-2} y\right|_{x_{r}=0}+\left.D_{r}^{2 s-2} y\right|_{x_{r}=X_{r}}=0, s=1,2, \ldots, n, r=1,2, \ldots, m, \\
& \ell_{3, n+s, r} y:=\left.D_{r}^{2 s-1} y\right|_{x_{r}=0}+\left.D_{r}^{2 s-1} y\right|_{x_{r}=X_{r}}=0, s=1,2, \ldots, n, r \neq j, r=1,2, \ldots, m, \\
& \ell_{3, n+p, j} y:=\left.D_{j}^{2 p-1} y\right|_{x_{j}=0}+\left.D_{j}^{2 p-1} y\right|_{x_{j}=X_{j}}+l_{p, j}^{2} y=0, p=1,2, \ldots, n, \\
& \ell_{p, j}^{1} y:=\left.\sum_{r=0}^{1} \sum_{q=0}^{m_{p, j}} b_{q, r, p, j} D_{j}^{q} y\right|_{x_{j}=r X_{j}} .
\end{aligned}
$$

Let $L_{3, j}$ be the operator of the problem $(58)-(61), V\left(L_{3, j}\right)$ be a system of root functions of the operator $L_{3, j}$. Let $L_{3} y:=L(D) y, y \in D\left(L_{3}\right), D\left(L_{3, j}\right):=\left\{y \in W_{2}^{2 n}(G): \ell_{3, s, j} y=0\right.$, $s=1,2, \ldots, 2 n, j=1,2, \ldots, m\}$. Let us consider for fixed $k(j) \in \mathbb{N}^{m-1}$ solutions of spectral problem for operator $L_{3}$ in a form of product (22).

To define an unknown function $z\left(x_{j}\right)$ we have the following problem

$$
\begin{aligned}
& \sum_{|\beta| \leq n} a_{\beta} \prod_{s=1, s \neq j}^{m}\left(k_{s} \pi X_{s}^{-1}\right)^{2 \beta_{s}} z^{\left(2 \beta_{j}\right)}\left(x_{j}\right)=\lambda z\left(x_{j}\right), \lambda \in \mathbb{C}, \\
& \ell_{3, s, j} y:=\left.z^{(2 s-1)}\right|_{x_{j}=0}-\left.z^{(2 s-1)}\right|_{x_{j}=X_{j}}=0, s=1,2, \ldots, n, \\
& \ell_{3, n+p, j} z:=\left.z^{(2 p-1)}\right|_{x_{j}=0}+\left.z^{(2 p-1)}\right|_{x_{j}=X_{j}}+\ell_{p, j}^{2} z=0, p=1,2, \ldots, n .
\end{aligned}
$$

Let $L_{3, k(j)}$ be the operator of the problem (62) - (64) and

$$
\begin{aligned}
& L_{3, k(j)} z:=\sum_{|\beta| \leq n} a_{\beta} \prod_{s=1, s \neq j}^{m}\left(\rho_{k, s}\right)^{2 \beta_{s}} z^{\left(2 \beta_{j}\right)}\left(x_{j}\right), z \in D\left(L_{3, k(j)}\right), \\
& D\left(L_{3, k(j)}\right):=\left\{y \in W_{2}^{2 n}\left(0, X_{j}\right): \ell_{3, s, j} z=0 ; s=1,2, \ldots, 2 n\right\} .
\end{aligned}
$$


Lemma 11. Let assumption $P_{1}$ holds true. Then for any fixed $a_{\beta} \in \mathbb{R}, b_{q, 0, p, j} \in \mathbb{R},|\beta| \leq n$, $k(j) \in \mathbb{N}^{m-1}$ operator $L_{3, k(j)}$ has eigenvalues (5) and the system of root functions $V\left(L_{3, k(j)}\right)$, which is total and minimal in the space $L_{2}\left(0, X_{j}\right)$.

2. If assumption $P_{2}$ holds true then system of functions $V\left(L_{3, k(j)}\right)$ is a Riesz basis in the space $L_{2}\left(0, X_{j}\right)$.

Proof. The Isospectrality of operators $L_{0,\left(k_{j}\right)}$ and $L_{3, k(j)}$ can be proved in the same way as in Lemma 4.

If assumption $P_{1}$ holds true we obtain following eigenfunctions of $L_{3, k(j)}$

$$
v_{1, k_{j}}\left(x_{j}, L_{3, k(j)}\right)=\frac{2}{\sqrt{2 X_{j}}} \cos \rho_{k, j} x_{j} X_{j}^{-1}, k_{j}=1,2, \ldots
$$

Root functions $v_{0, k_{j}}\left(x_{j}, L_{3, k(j)}\right)$ of the operator $L_{3, k(j)}$ we defined by

$$
v_{0, k_{j}}\left(x_{j}, L_{3,\left(k_{j}\right)}\right)=\frac{2}{\sqrt{2 X_{j}}} \sin \rho_{k, j} X_{j}^{-1} x_{j}+\sum_{p=1}^{n} \eta_{2, p, j, k} y_{1, p, k_{j}}\left(x_{j}, \lambda_{k}\right), k_{j}=1,2, \ldots,
$$

where numbers $\eta_{2, p, j, k}$ defined by equation (56). Therefore, operator $L_{3, k(j)}$ has a system of root functions (65), (66). If we consider formulas (31), (32), it is easy to see that operator $L_{3, k(j)}$ is a partial case of operator $A_{2, p, j}$. Therefore from Lemma 7 it follows that the system $V\left(L_{3, k(j)}\right)$ is total and minimal in the space $L_{2}\left(0, X_{j}\right)$ and the biorthogonal system $W\left(L_{3, k(j)}\right):=$ $\left\{w_{k_{j}}\left(x_{j}, L_{3,\left(k_{j}\right)}\right) \in L_{2}\left(0, X_{j}\right), k_{j}=1,2, \ldots\right\}$ exists.

Let assumption $P_{2}$ takes place. From (49) we can get $\sum_{p=1}^{n}\left|c_{1, p, j, k}\right|^{2} \leq C_{15}<\infty$. Then the system $V\left(L_{3, k(j)}\right)$ is normalized and from Lemma 9 it follows that the system $V\left(L_{3, k(j)}\right)$ is a Riesz basis in the space $L_{2}\left(0, X_{j}\right)$.

Let us define root functions of the operator $L_{3, j}$ by equations

$$
v_{k}\left(x, L_{3, j}\right)=v_{k_{j}}\left(x_{j}, L_{3, k(j)}\right) \prod_{r=1, r \neq j}^{m} \tau_{r, k_{r}}\left(x_{r}\right), k \in \mathbb{N}^{m} .
$$

Using the system $V\left(L_{3, j}\right)$ of root functions (67) we can define an operator $R\left(L_{3, j}\right):=\prod_{p=1}^{n} R\left(L_{2, p, j}\right)$ $\in \Gamma_{j}\left(L_{0}\right), \quad S\left(L_{3, j}\right):=\sum_{p=1}^{n} S\left(L_{2, p, j}\right)$, which acts from system of functions $V\left(L_{0}\right)$ to the system $V\left(L_{3, j}\right)$.

Theorem 6. Let assumption $P_{1}$ holds. Then for any fixed $a_{\beta} \in \mathbb{R}, b_{q, 0, p, j} \in \mathbb{R},|\beta| \leq n$ the operator $L_{3, j}$ has eigenvalues (6) and the system of eigenfunctions $V\left(L_{3, j}\right)$, which is total and minimal in the space $L_{2}(G)$.

2. If assumptions $P_{1}-P_{3}$ hold, then the system of functions $V\left(L_{3, j}\right)$ is a Riesz basis in the space $L_{2}(G)$.

Proof. Let assumption $P_{1}$ holds. Then according to Lemma 11 for any $k(j) \in \mathbb{N}^{m-1}$ there exists a system of functions $W\left(L_{3, k(j)}\right)=\left\{w_{k_{j}}\left(x_{j}, L_{3, k(j)}\right), k_{j}=1,2, \ldots,\right\}$ which is biorthogonal 
to the system $W\left(L_{3, k(j)}\right)$. Therefore we can define elements of the system $W\left(L_{3}\right)$, which is biorthogonal in the space $L_{2}(G)$ to the system $V\left(L_{3}\right)$, by the following way

$$
w_{k}\left(x, L_{3, j}\right)=w_{k_{j}}\left(x_{j}, L_{3, k(j)}\right) \prod_{r=1, r \neq j}^{m} \tau_{r, k_{r}}\left(x_{r}\right), k \in \mathbb{N}^{m} .
$$

So the system of functions $V\left(L_{3, j}\right)$ is total and minimal in the space $L_{2}(G)$. Last part of the proof can be made analogously to Theorem 5 .

\section{PROOFS OF THE MAIN THEOREMS}

Let us consider spectral problem for $p=1,2, \ldots, n, j=1,2, \ldots, m$

$$
\begin{aligned}
& L(D) y:=\sum_{|\beta| \leq n} a_{\beta} D^{2 \beta} y=\lambda y, \\
& \ell_{p, j} y:=\left.D_{j}^{2 p-2} y\right|_{x_{j}=0}+\left.D_{j}^{2 p-2} y\right|_{x_{j}=X_{j}}=0, p=1,2, \ldots, n, j=1,2, \ldots, m, \\
& \ell_{n+p, j} y:=\left.D_{j}^{2 p-1} y\right|_{x_{j}=0}+\left.D_{j}^{2 p-1} y\right|_{x_{j}=X_{j}}+\left.\sum_{r=0}^{1} \sum_{q=0}^{m_{p, j}} b_{q, r, p, j} D_{j}^{q} y\right|_{x_{j}=r X_{j}}=0 .
\end{aligned}
$$

Proof. Proof of Theorem 1.

Let

$$
R(L):=\prod_{j=1}^{m} R_{j}\left(L_{3}\right), R(L):=E+\sum_{j=1}^{m} S_{j}\left(L_{3}\right) \in \Gamma\left(L_{0}\right) .
$$

Root functions of the operator $L$ of problem (68) - (70) we can define in the form

$$
\begin{aligned}
& v_{k}(x, L)=\prod_{j=1}^{m} v_{k_{j}}\left(x_{j}, L_{3, k(j)}\right), k \in \mathbb{N}^{m}, \\
& v_{k}(x, L)=v_{k}\left(x, L_{0}\right)+\sum_{j=1}^{m} S\left(L_{3, j}\right) v_{k}\left(x, L_{0}\right) .
\end{aligned}
$$

So $V(L):=\left\{v_{k}(x, L) \in L_{2}(G): v_{k}(x, L)=R(L) v_{k}\left(x, L_{0}\right), k \in \mathbb{N}^{m}\right\}$ is a system of root functions. Since biorthogonal system of functions $w_{k}(x, L)=\prod_{j=1}^{m} w_{k_{j}}\left(x_{j}, L_{3, k(j)}\right), k \in \mathbb{N}^{m}$, exists, then we have the proof of the theorem.

If assumptions of Theorem 2 hold true, Theorem 6 takes place too. So $R\left(L_{3, j}\right) \in\left[L_{2}(G)\right]$, $j=1,2, \ldots, m$. If we consider equation (71), we will obtain $R(L), R^{-1}(L) \in\left[L_{2}(G)\right]$. Therefore $V(L)$ is a Riesz basis of the space $\left[L_{2}(G)\right]$ by definition.

Remark 5. There exist positive numbers $C_{1}(L), C_{2}(L)$ such that for any function

$$
f(x)=\sum_{|k|=0}^{\infty} f_{k} v_{k}(x, L) \in L_{2}(G), f_{k}=\left(f, w_{k} ; L_{2}(G)\right), k \in \mathbb{N}^{m},
$$

holds the following inequality

$$
C_{16}\left\|f ; L_{2}(G)\right\|^{2} \sum_{|k|=0}^{\infty}\left|f_{k}\right|^{2} \leq C_{17}\left\|f ; L_{2}(G)\right\|^{2} .
$$


Let us consider boundary problem

$$
\begin{aligned}
& L(D) y:=\sum_{|\beta| \leq n} a_{\beta} D^{2 \beta} y=f, \\
& \ell_{s, j} y:=\left.D_{j}^{2 s-2} y\right|_{x_{j}=0}+\left.D_{j}^{2 s-2} y\right|_{x_{j}=X_{j}}=0, j=1,2, \ldots, m, \\
& \ell_{s+n, j} y:=\left.D_{j}^{2 s-1} y\right|_{x_{j}=0}+\left.D_{j}^{2 s-1} y\right|_{x_{j}=X_{j}}+\left.\sum_{r=0}^{1} \sum_{q=0}^{m_{s}} b_{q, r, s, j} D_{j}^{q} y\right|_{x_{j}=x_{j, r}}=0, \\
& f(x)=\sum_{|k|=0}^{\infty} \sum_{r \in Q_{m}} f_{r, k} v_{r, k}(x, L), f_{r, k}=\left(u, w_{r, k}\left(x, L ; L_{2}(G)\right), r \in Q_{m}, k \in \mathbb{N}^{m} .\right.
\end{aligned}
$$

We will search a solution of the problem in the form of series

$$
u(x)=\sum_{|k|=0}^{\infty} \sum_{r \in Q_{m}} u_{r, k} v_{r, k}(x, L) .
$$

We will use the following notations: $f_{r+s, k}:=\prod_{j=1}^{m} f_{r_{j}+s_{j}, k_{j}}, \quad \xi_{r, k}:=\prod_{j=1}^{m} \xi_{r_{j}, k_{j}}, \quad \xi_{r_{j}, k_{j}}:=$ $D_{\rho_{k, j}} \sum_{|\beta| \leq n} a_{\beta} \rho_{k}^{2 \beta}$. If we substitute series (77), (78) into formula (74), we can get

$$
\begin{aligned}
& u_{r, k}=\sum_{j=1}^{m} \sum_{r_{j}+s_{j} \leq 1} \lambda_{k}^{-1-|s|} f_{r+s, k} \xi_{r+s, k}, k \in \mathbb{N}^{m}, r \in Q_{m}, \\
& u(x)=\sum_{|k|=0}^{\infty} \sum_{r \in Q_{m}} \sum_{j=1}^{m} \sum_{r_{j}+s_{j} \leq 1} \lambda_{k}^{-1-|s|} f_{r+s, k} \xi_{r+s, k} v_{k}(x, L) .
\end{aligned}
$$

If we apply Cauchy inequality to (78) we will obtain the inequality $\left|u_{r, k}\right|^{2} \leq C_{18} \sum_{q \in Q_{m}}\left|u_{q, k}\right|^{2}$. Therefore, using inequality (73) we can get

$$
\left\|u ; L_{2}(G)\right\|^{2} \leq C_{19}(L)\left\|f ; L_{2},(G)\right\|^{2}, C_{19}=C_{18} C_{17} C_{16}^{-1} .
$$

Let us suppose that coefficient of derivative $D_{x_{m}}^{2 n}$ equals 1 and give a proof for variable $x_{m}$. Let us show that $D_{m}^{2 n} u(x) \in L_{2}(G)$. For any fixed $k(m) \in \mathbb{N}^{m-1}$ we consider boundary problem

$$
\begin{aligned}
& \sum_{|\beta| \leq n}(-1)^{\beta_{m}} a_{\beta} \prod_{s=1}^{m-1} \mu_{k, s}^{\beta_{s}} y^{\left(2 \beta_{m}\right)}\left(x_{m}\right)=f\left(x_{m}\right), \\
& \ell_{2, s, m} y:=\left.y^{(2 s-2)}\right|_{x_{m}=0}+\left.y^{(2 s-2)}\right|_{x_{m}=X_{m}}=0, s=1,2, \ldots, n, \\
& \ell_{2, n+s, m} y:=\left.y^{(2 s-1)}\right|_{x_{m}=0}+\left.y^{(2 s-1)}\right|_{x_{j}=X_{m}}=0, s \neq p, s=1,2, \ldots, n, \\
& \ell_{2, n+p, m} y:=\left.y^{(2 p-1)}\right|_{x_{m}=0}+\left.y^{(2 p-1)}\right|_{x_{m}=X_{m}}+\ell_{p, m}^{1} z=0, \\
& \ell_{p, m}^{2} y:=\left.\sum_{r=0}^{1} \sum_{q=0}^{m_{p, m}} b_{q, r, p, j} y^{(q)}\right|_{x_{m}=x_{m, r}} .
\end{aligned}
$$

Let us consider functions $y\left(x_{m}\right), f\left(x_{m}\right)$ in a form of series which is constructed using system of root functions of operator $L_{2, k(m), p}:=L_{2, k(m)}$ :

$$
y=\sum_{k_{m}=1}^{\infty} \sum_{s=0}^{1} y_{s, k_{m}, p} v_{s, k_{m}}\left(x, L_{2, k(m), p}\right), f=\sum_{k_{m}=1}^{\infty} \sum_{s=0}^{1} f_{s, k_{m}, p} v_{s, k_{m}}\left(x, L_{2, k(m), p}\right) .
$$


If we substitute this expressions into equation (81) we can obtain $y_{0, k_{m}, p}=\lambda_{k}^{-1} f_{0, k_{m}}, y_{1, k_{m}}=$ $-\lambda_{k}^{-2} \xi_{0, k_{m}} f_{1, k_{m}, p}+\lambda_{k}^{-1} f_{1, k_{m}, p}$. Therefore,

$$
y=\sum_{k_{m}=1}^{\infty}\left(\lambda_{k}^{-1} f_{0, k_{m}, p} v_{0, k_{m}}\left(x, L_{2, k(m), p}\right)+\left(-\lambda_{k}^{-2} \xi_{0, k_{m}} f_{1, k_{m}, p}+\lambda_{k}^{-1} y_{1, k_{m}, p}\right) v_{1, k_{m}}\left(x, L_{2, k(m)}, p\right)\right) .
$$

Let us consider sequence of numbers $\gamma_{m, k}:=\rho_{m, k} \lambda_{k}^{-1}, k_{m}=1,2, \ldots$. The sequence $\gamma_{m, k}=$ $\rho_{m, k} \lambda_{k}^{-1}=1-\lambda_{k}^{-1} \sum_{|\beta| \leq n, \beta_{m}<n} a_{\beta} \prod_{s=1}^{m}\left(\rho_{m, s}\right)^{2 \beta_{s}} \rightarrow 1, k_{m} \rightarrow \infty$ is convergent.

Therefore $0<C_{21} \leq \gamma_{m, k} \leq C_{20}<\infty$.

Consider the system of functions

$$
V_{m, k, p}:=\left\{v_{r, k_{m}, p}(x) \in L_{2}\left(0, X_{m}\right): v_{r, k_{m}, p}(x):=\gamma_{m, k} v_{r, k_{m}}\left(x, L_{2, k(m), p}\right), k_{m}=1,2, \ldots\right\} .
$$

If assumption of Lemma 10 holds, from the last inequality it follows that the system $V_{m, k, p}$ is a Riesz basis in the space $L_{2}\left(0, X_{m}\right)$.

Let $V_{1, m, k, p}:=\left\{v_{1, r, k_{m}, p}(x) \in L_{2}\left(0, X_{m}\right): v_{1, r, k_{m}, p}(x):=\lambda_{k}^{-1} D_{m}^{2 n_{v_{r}, k_{m}}}\left(x, L_{2, k(m), p}\right), \quad r=\right.$ $\left.0,1, k_{m}=1,2, \ldots\right\}$.

Since operator $D_{m}^{2 n}$ commutate with the involution $I_{m}$, then analogously to Lemma 4 we can prove that the system $V_{1, m, k, p}$ is total and minimal in the space $L_{2}\left(0, X_{m}\right)$.

Let $v_{2, r, k_{m}, p}(x):=v_{1, r, k_{m}, p}(x)-v_{0, r, k_{m}, p}(x), r=0,1, k_{m}=1,2, \ldots$ From formulas (28) - (30) it follows $v_{2,0, k_{m}, p}(x)=\vartheta_{1, k_{m}, p} \rho_{m, k, p}^{-1} z_{0, q}\left(x_{j}, k_{j}, \lambda_{k}\right)+\sum_{s=2}^{m} \vartheta_{s, k_{m}, p} z_{0, q}\left(x_{j}, k_{j}, \lambda_{k}\right)$, where $\left|\vartheta_{s, k_{m}, p}\right| \leq$ $C_{22}<\infty$. Therefore, $\sum_{k_{m}=1}^{\infty} \sum_{r=0}^{1}\left(v_{2, r, k_{m}, p}(x) ; L_{2}\left(0, X_{m}\right)\right)^{2}<\infty$.

So the system $V_{m, k, p}$ is a Riesz basis in the space $L_{2}\left(0, X_{m}\right)$ and the system $V_{1, m, k, p}$ is total and minimal in the space $L_{2}\left(0, X_{m}\right)$. Therefore, from Bari's theorem [6] we obtain: the system $V_{1, m, k, p}$ is a Riesz basis in $L_{2}\left(0, X_{m}\right)$ and therefore, the operator $R\left(V_{1, m, k, p}\right): V\left(L_{0, k_{m}} \rightarrow V_{1, m, k}\right.$ is bounded. The product of this operators is also continuous in the space $L_{2}\left(0, X_{m}\right)$.

So for any fixed $k(m) \in \mathbb{N}^{m-1}$ inequality

$$
\sum_{k_{m}=1}^{\infty} \sum_{r=0}^{1}\left(D_{m}^{2 n} u, v_{r, k}(x, L) ; L_{2}(G)\right)^{2} \leq C_{23} \sum_{k_{m}=1}^{\infty} \sum_{r=0}^{1}\left(f, v_{r, k}(x, L) ; L_{2}(G)\right)^{2}
$$

takes place. If we summarize by $k(m) \in \mathbb{N}^{m-1}$, we will get

$$
D_{x_{m}}^{2 n}\left|u ; L_{2}(G)\right|^{2} \leq C_{23}\left|f ; L_{2}(G)\right|^{2} .
$$

The assumption made in the inequality proof is insignificant since if assumption $P_{3}$ holds coefficients of the hiest degree derivatives is nonequal to zero and has the same sign.

Analogously we can prove that $D_{j}^{2 n} u(x) \in L_{2}(G), j=1,2, \ldots, m-1$ for any other variables. So using the definition of norm in the space $L_{2}(G)$, we obtain the proof of the Theorem 3.

\section{REFERENCES}

[1] Baranetskij Ya. O. Nonlocal boundary value problem for equations with constant coefficients. Visn. Lviv Polytech. National Univ. Ser. Phys. Math. Sci. 1997, 320, 13-15. (in Ukrainian) 
[2] Baranetskij Ya., Basha A. Initial Nonlocal multipoint problem for differential-operator equations of order $2 n$. J. Math. Sci. 2016, 217 (2), 176-186. doi:10.1007/s10958-016-2965-0

[3] Baranetskij Ya.O., Kalenyuk P.I., Kolyasa L.I., Kopach M.I. The nonlocal problem for the differential-operator equation of the even order with the involution. Carpathian Math. Publ. 2017, 9 (2), 109-119. doi:10.15330/cmp.9.2.109-119

[4] Baranetskij Ya.O., Demkiv I.I., Ivasiuk I.Ya., Kopach M.I. The nonlocal problem for the differential equations the order $2 n$ with an unbounded operator coefficients with the involution. Carpathian Math. Publ. 2018, 10 (1), 14-30. doi: $10.15330 / \mathrm{cmp} \cdot 10.1 .14-30$

[5] Baranetskij Ya.O., Kalenyuk P.I., Kolyasa L.I., Kopach M.I. The nonlocal multipoint problem for an ordinary differential equations of even order with the involution. Math. Stud. 2018, 49 (1), 80-94. doi: $10.15330 / \mathrm{ms} .49 .1 .80-94$

[6] Baranetskij Ya.O., Kalenyuk P.I., Kolyasa L.I. Spectral Properties of Nonself-Adjoint Nonlocal Boundary-Value Problems for the Operator of Differentiation of Even Order. Ukr. Mat. J. 2018, 70 (6), 851-865. doi: 10.1007/s11253018-1538-4 (translation of Ukr. Math. Zh. 2018, 70 (6), 739-751. (in Ukrainian))

[7] Borok V.M., Fardigola L. V. Nonlocal well-posed boundary-value problems in a layer. Math. Notes. 1990, 48 (1), 635-639.

[8] Borok V.M. Initial On correct solvability of a boundary value problem in an infinite layer for linear equations with constant coefficients. Math. USSR Izv. 1971, 5(4), 935-953.

[9] Burskii V.P., Buryachenko E.A. Some aspects of the nontrivial solvability of homogeneous Dirichlet problems for linear equations of arbitrary even order in the disk. Mat. Zametki. 2005, 77 (4), 498-508. doi:10.4213/mzm2508.

[10] Buryachenko E.A. Solvability of the homogeneous Dirichlet problem in a disk for equations of order $2 m$ in the case of multiple characteristics with inclination angles. J. Math. Sci. 2009, 160 (3), 319-329.

[11] Dikopolov G.V., Shilov G.E. O korrektnykh kraevykh zadachakh dlya uravnenii v chastnykh proizvodnykh $v$ poluprostranstve. Izv. AN SSSR. Ser. mat. 1960, 24 (3), 369-380.

[12] Dikopolov G.V. On boundary-value problems for differential equations with constant coefficients in a half-space. Mat. Sb. 1962, 59, 215-228.

[13] Il'kiv V.S. Nonuniqueness conditions for the solutions of the Dirichlet problem in a unit disk in terms of the coefficients of differential equation. J. Math.Sci. 2013, 194 (2), 182-197.

[14] Irgashev B.Yu. Boundary problem for equations of high-even order. Vesn. Volg. gos. univ. Ser. Math. Phys. 2016, 334 (3), 6-18. doi: 10.15688/jvolsu1.2016.3.1

[15] Irgashev B.Yu. On one boundary-value problem for an equation of higher even order. Russian Math. (Iz. VUZ). 2017, $61(9), 10-18$.

[16] Irgashev B.Yu. On spectral problem for one equation of high even order. Russian Math. (Iz. VUZ). 2016, 60 (7), $37-46$.

[17] Fardigola L.V. Integral boundary problem in a layer. Math. Notes. 1993, 53 (6), 644-649.

[18] Gading L. Dirichlet's problem and the vibration problem for linear elliptic partial differential equations with constant coefficients. Proc. Symp. Spectral Theory Diff. Probl. Stillwater, Oklahoma. 1955, 291-299.

[19] Gokhberg I. Ts., Krein M.G. Introduction to the Theory of Linear Non Self-Adjoint Operators. Nauka, Moscow, 1965. (in Russian)

[20] Koshanov B. D., Soldatov A. P. Boundary value problem with normal derivatives for a higher-order elliptic equation on the plane. Differential Equations. 2016, 52 (12), 1594-1609.

[21] Mosolov P.P. A generalized first boundary-value problem for a certain class of differential operators. I. Mat. Sb. (N.S.) 1962, 57 (3), 333-374.

[22] Mosolov P.P. The Dirichlet problem for partial differential equations. Izv. Vyssh. Uchebn. Zaved. Mat. 1960, 3, 213-218. 
[23] Pavlov A.L. Solvability of boundary value problems in a half-space for differential equations with constant coefficients in the class of tempered distributions. Siberian Math. J. 2013, 54 (4), 697-712.

[24] Pavlov A.L. Correctness of general boundary-value problems in a half-space for differential equations with constant coefficients in the classes of functions of power growth and decay. J. Math.Sci. 2011, 173 (4), 408-440. doi: 10.1007/s10958-011-0258-1

[25] Palamodov V.P. The conditions for proper solvability in the large of a class of equations with constant coefficients. Dokl. Akad. Nauk SSSR. 1960, 132 (3), 528-530.

[26] Palamodov V. P. Wel l-posed boundary problems for partial differential equations on a half-space. Izv. Akad. Nauk SSSR. Ser. Mat., 1960, 24 (3), 381-386.

[27] Ptashnyk B.I., Il'kiv V.S, Kmit' I.Ya., Polischuk V.M. Nonlocal Boundary-Value Problems for Partial Differential Equations. Kyiv, Naukova Dumka, 2002. (in Ukrainian)

[28] Sabitov K.B. The Dirichlet Problem for Higher-Order Partial Differential Equations. Math. Notes. 2015 , 97 (2), 255-267. doi: 10.4213/mzm9286

[29] Shkalikov A. A. On the basis problem of the eigenfunctions of an ordinary differential operator. Rus. Math. Surv. 1979, 34 (5), 249-250.

Received 09.05.2018

Баранецький Я.О., Івасюк І.Я., Каленюк П.І., Соломко А.В. Нелокальна крайова задача зі збуреннями умов антиперіодичності для еліптичного рівняння з постійними коефічієнтами // Карпатські матем. публ. - 2018. - Т.10, №2. - С. 215-234.

У роботі в обмеженому m-вимірному паралелепіпеді методом Фур'є досліджується задача з нелокальними крайовими умовами, які $є$ збуреннями умов антиперіодичності. Вивчено властивості оператора перетворення $R: L_{2}(G) \rightarrow L_{2}(G)$, який встановлює зв'язок між самоспряженим оператором $L_{0}$ задачі з умовами антиперіодичності та оператором $L$ збуреної нелокальної задачі $R L_{0}=L R$.

Також побудовано комутативну групу операторів перетворення $\Gamma\left(L_{0}\right)$. Встановлено, що кожному операторові перетворення $R \in \Gamma\left(L_{0}\right): L_{2}(G) \rightarrow L_{2}(G)$ відповідає деяка абстрактна нелокальна задача і навпаки. Побудовано систему $V(L)$ кореневих функцій оператора $L$, яка містить нескінченне число приєднаних функцій. Визначено умови, при яких система $V(L)$ повна та мінімальна в просторі $L_{2}(G)$, та умови, при яких вона є базою Ріса у просторі $L_{2}(G)$.

У випадку, якщо система $V(L) \in$ базою Ріса в просторі $L_{2}(G)$, встановлено достатні умови, при яких нелокальна задача має єлиний розв'язок у вигляді ряду Фур'є за системою $V(L)$.

Ключові слова і фрази: диференціально-операторне рівняння, власні функції, база Ріса. 